\title{
A Study on Complication and Monitoring of Warfarin in Post-Valve Surgery
}

\author{
Shrestha $\mathrm{P}^{1}$ Koirala $B{ }^{2}$ Shrestha $N,{ }^{1}$ Thapa $\mathrm{P}^{1}$ \\ 'Department of Pharmacy, Kathmandu University, Dhulikhel, Kavre, Nepal, ${ }^{2}$ Department of Cardiac surgery, Sahid Gangalal \\ National Heart Centre (SGNHC), Nepal
}

\begin{abstract}
Introduction: This study was carried out to determine the incidence of complication related to warfarin in patients with valve surgery and identify potential risk factors for complication and study its monitoring aspects.
\end{abstract}

Methods: A combined retrospective and prospective observational study including a total of 185 patients who underwent mechanical valve replacement in Shahid Gangalal National Heart Centre. The study was conducted from 4 November 2006 till 1 February 2007.

Results: There were a total of 141 episodes of bleeding. Among them significant bleeding occurred in $15.7 \%$ patients, major bleeding was 3.2 per 100 patient-years $(3.8 \%)$ and minor bleeding was 11.8 per 100 patient-years $(11.9 \%)$. Epistaxis $(16.8 \%)$ was the most common bleeding complication. Menorrhagia was the most common bleeding complication in females with 20.5 per 100 patient-years (27.4\%). Thromboembolic complications occurred at the rate of 2.3 per 100 patient-years. Patients on warfarin were outside the INR target range $67.8 \%$ of the time, with $21 \%$ INR values above range and $46.8 \%$ INR values below range. However, dose adjustment was done only $31.8 \%$ of times when INR was outside range.

Conclusions: There is high incidence of bleeding complication in patients on warfarin and hypertension is significantly associated with bleeding. Difficulty in tightly controlling INR probably is related to high incidence of bleeding. Better patient education, stricter adjustment of INR, frequent monitoring of INR at peripheral hospitals and standardization of the test at different hospitals are suggested to reduce the warfarin related complications.

Key Words: bleeding complication, heart valve surgery, warfarin

\section{INTRODUCTION}

Mechanical prostheses are more thrombogenic than bioprostheses or homografts, and hence patients with mechanical valves require lifelong anticoagulant therapy. ${ }^{1}$
The annual rate of thromboembolic complications is $8 \%$ in patients with mechanical heart valves not taking anticoagulant therapy. ${ }^{2}$
Correspondence:
Mrs. Poonam Shrestha
Department of Pharmacy
Kathmandu University,
Dhulikhel, Kavre, Nepal.
Email: pshr0113@hotmail.com 
Increasing intensity of anticoagulation is one of the major risk factor for bleeding complication of warfarin. Higher target international normalization ratio (INR) is required for patients with mechanical heart valve than for other indications. ${ }^{3}$ In addition, there is enhanced sensitivity to warfarin immediately after heart valve replacement. The dose requirement of warfarin to achieve a given INR varies considerably between the immediate postoperative period and long-term followup. ${ }^{4}$

So the aim of this study is to determine the incidence of complication related to warfarin in patients with valve surgery and identify potential risk factors for complication in these patients as well as to study its monitoring aspects.

\section{METHODS}

A combined prospective plus retrospective observational study was conducted at Shahid Gangalal National Heart Center (SGNHC), Bansbari, Kathmandu, Nepal. The study was carried out for the duration of 3 months November 15, 2006 to 16 February 16, 2007. A total of 185 patients receiving treatment with warfarin after undergoing mechanical valve replacement at SGNHC were taken. This study was approved by ethical review committee Kathmandu University, School of Medical Science with the protocol approval number IRC-KUSMS 05/07. Ethical review committee of Shahid Gangalal National Heart Center also approved this study.

After informed consent, patients starting treatment during the study period were followed for the duration of 3 months to identify occurrence of complication and monitoring related to warfarin. The Patients already undergoing treatment when the project was started were interviewed to investigate any occurrence of complication of warfarin in the past.

\section{Working Definition ${ }^{5}$}

Nuisance bleeding is defined as self-limited bleeding which will often be adequately treated with local measures and usually does not require specific medical interventions. It also usually does not result in changes in anticoagulant medications or their dose and frequency. It includes self-limiting epistaxis, menorrhagia and bruising.

Minor bleeding requires some form of medical intervention and may result in changes in medication type, dose or frequency. It is often significantly inconvenient for the patient. Examples of minor bleeding include epistaxis requiring nasal packing and most forms of post-surgical bleeding in patients receiving anticoagulants.

Major bleeding requires a significant medical intervention (such as transfusion, endoscopy or surgery), will routinely result in withholding or discontinuing of anticoagulants, and may cause long-term morbidity or death

The data collection and statistical analysis were done by statistical package for social sciences version 13 for windows. Chi-square test was used to determine the association between complication and the different population parameters. Chi-square analysis was also used to evaluate the association between INR and dose adjustment practice. It was also used to evaluate association between different other variables. A p-value less than 0.05 was considered statistically significant.

\section{RESULTS}

A total of 185 patients were included in the study. Among them $68(36.8 \%)$ patients were within three months post surgery and $117(63.2 \%)$ were beyond three months post surgery. The cumulative follow up for these patients was 220.7 patient-years. In this study, proportion of male and female was almost equal $(m=51 \%, f=49 \%)$. Mean age was $29.6 \pm 12.4$. Half of the study group (51\%) had mitral valve replacement (MVR), 25\% had aortic valve replacement (AVR) and $24 \%$ had double valve replacement (DVR).

A total of 141 bleeding events $(63.9$ per 100 patientyears) occurred in 106 patients. Among them significant bleeding occurred in $15.7 \%$ patients (major bleeding complication was 3.2 per 100 patient-years $(3.8 \%)$ and minor bleeding was 11.8 per 100 patient-years (11.9\%). However, when non-significant bleeding was also included, total $57.3 \%$ experienced bleeding (nuisance bleeding was 48.9 per 100 patient-years $(41.6 \%)$. Epistaxis was the most common bleeding event $(16.8 \%)$ and menorrhagia was the commonest among women $(27.4 \%$ of total women, 20.5 per 100 patient-years).

Pericardial bleeding was the most common major bleeding complication. Gingivial bleeding, epistaxis and GI bleeding were the most common minor bleeding events.

Table 1. Incidence of major bleeding events

\begin{tabular}{lll}
\hline Major Bleeding & $\begin{array}{l}\text { No. of } \\
\text { patients (\%) } \\
(\mathbf{n = 1 8 5 )}\end{array}$ & $\begin{array}{l}\text { Per 100 } \\
\text { patient- } \\
\text { years }\end{array}$ \\
\hline Pericardial bleeding & $2(1.1)$ & 0.9 \\
Hemoptysis & $1(0.5)$ & 0.4 \\
Epistaxis & $1(0.5)$ & 0.4 \\
Gastrointestinal bleeding & $1(0.5)$ & 0.4 \\
\hline Menorrhagia & $1(0.5)$ & 0.4 \\
\hline Hematoma & $1(0.5)$ & 0.4 \\
\hline
\end{tabular}


Shrestha et al. A Study on Complication and Monitoring of Warfarin in Post-Valve Surgery

Table 2. Incidence of type of valve replacement and bleeding complication

\begin{tabular}{lllllll}
\hline \multirow{2}{*}{ Bleeding Category } & & \multicolumn{2}{c}{ No. of patients (\%, per 100 patient-years) } & p-value* \\
& & MVR $(\mathbf{n}=95)$ & DVR $(\mathbf{n}=44)$ & AVR (n=46) & \\
\hline Major & Occurred & $1(1.1,0.8)$ & $2(4.5,5.2))$ & $4(8.7,7.6)$ & 0.079 \\
Minor & occurred & $8(8.4,8.5)$ & $9(20.5,23.4)$ & $5(10.9,11.4)$ & 0.121 \\
\hline
\end{tabular}

* chi-square test

\section{Association of bleeding complication with type of valve replacement}

There was no association ( $P>0.05)$ between type of prosthesis and various types of bleeding complication.

\section{Risk factor for bleeding}

Eleven bleeding complication occurred in 14 patients with hypertension. Statistically significant association $(\mathrm{P}<0.05)$ was found between hypertensive patients and major type bleeding.

Statistical analysis showed that there was no significant association $(P>0.05)$ between sex and bleeding. Similarly, no significant association was seen of bleeding complication with age $(P>0.05)$.

\section{Thromboembolic Complication}

Five thromboembolic complications (Transient ischemic attack of limbs- one patient, hemiparesis - three patients, acute left limb ischemia - one patient) developed in five patients. So, it occurred at the rate of 2.3 per 100 patient-years. Total $20 \%$ of thromboembolic complication occurred when the INR was within the therapeutic range.

\section{INR Monitoring}

Overall, out of total 1103 INR readings $46.8 \%$ (516) INR was below the target range and $21 \%$ (232) was above target range. Only $32.2 \%$ (355) INR was within target range (Figure 1).

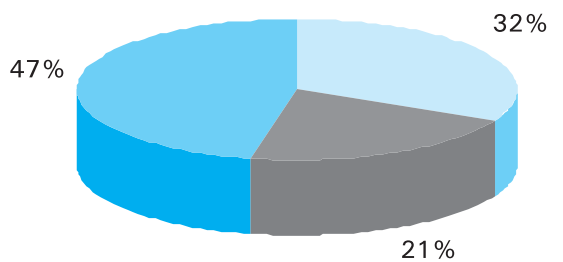

Within range Above range Below range

Figure 1. Categorization of INR readings within and outside range

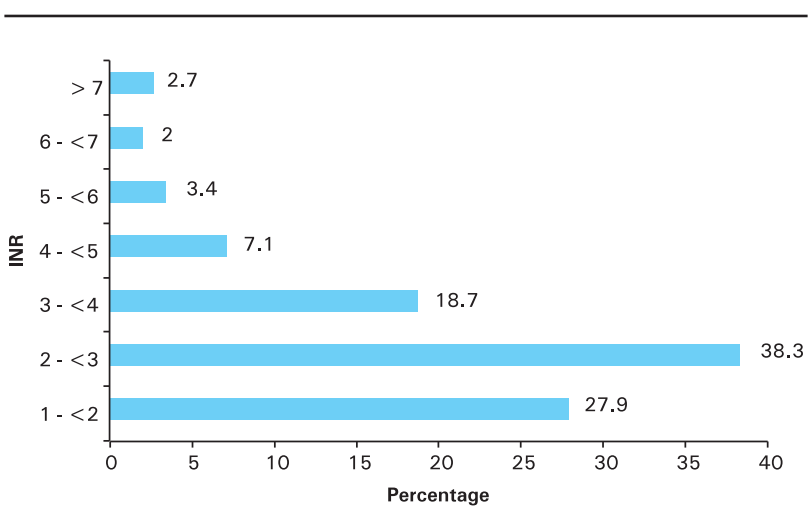

Figure 2. Fluctuation in INR of the patients

\section{Dose Adjustment}

Statistical analysis showed that there was significant association ( $p<0.05$ ) between dose adjustment and INR. Out of 1103 total INR readings, 749 were outside target range among which there were 238 (31.8\%) INR reading in which dose adjustment was not done. When the INR was above target range $82.4 \%$ of times the dose adjustment was done. Whereas, when the INR was below target range dose adjustment was done only $61.8 \%$ of times.

\section{Hospitalization}

There were 41 cases of hospitalization in 36 (19.45\%) patients. Two patients had complication related to warfarin when their INR was in the therapeutic range. Seven patients required hospitalization for reasons unconnected with warfarin therapy. Eighteen patients were hospitalized due to underwarfarinization and 14 due to overwarfarinization. This study shows that underwarfarinzation requiring hospitalization was more common than overwarfarinization.

\section{DISCUSSION}

In this study 141 bleeding events (63.9 per 100 patient-years) occurred in 106 patients which is three fold higher than the trend shown by Acar et al. 120.5 per 100 patient years). ${ }^{6}$ The high incidence of bleeding seen in this study could be due to variation in defining bleeding events. 
In this study, nuisance bleeding was the most common bleeding (48.9 per 100 patient-years). Major bleeding occurred at the rate of 3.2 per 100 patient-years which is consistent with the results of Aspinall et al. ${ }^{7}$ whereas minor bleeding occurred at the rate of 11.8 per 100 patient-years which is twice as higher than reported by other studies. ${ }^{7,8}$ This difference in bleeding event could be due to variation in number of patients and patient years involved in the study. Moreover, it could also be due to the variation in bleeding categorization and warfarin management. Beside this, present study involved patient with restricted indication, having valve replacement only.

Studies $^{9,10}$ have shown that epistaxis is a common bleeding event in patients on warfarin which is consistent with our finding. Epistaxis occurred in $16.8 \%$ of total patients in our study.

Pisoni et al. ${ }^{11}$ from UK reported that menorrhagia is common in women receiving oral anticoagulation. Similar findings were observed in this study with high incidence of menorrhagia.

This study identified that patients with AVR had highest incidence of major bleeding complication, while patients with MVR had the least incidence of major bleeding which is inconsistent with the finding of Cannegieter et al. $^{2}$ which states that prosthesis in mitral position increased the risk of bleeding almost twice as compared with the aortic position. This could be due to small number of patients in subgroups with AVR $(n=46)$ and DVR $(n=44)$, which might have overestimated the result.

There are many patient characteristics associated with bleeding complications during warfarin therapy. ${ }^{12}$ Hypertension is one of the known risk factor that increases the risk of bleeding. ${ }^{13}$ Eleven out of 14 patients with hypertension had bleeding events. The finding of this study also supports the similar trend. We found that there exists statistically significant association $(P<0.05)$ between hypertension and major type bleeding.

Some studies ${ }^{14,15}$ have noted an increased frequency of bleeding in women treated with warfarin. However, this study found higher incidence of bleeding in male (74.4\%) than female $(60 \%)$ but it was not statistically significant. Several studies ${ }^{8,16}$ have suggested association of older age with bleeding complication. However, we did not observe such increasing trend in major type of bleeding with increasing age.

The rate of thromboembolic complication (2.3 per 100 patient-years) seen in this study is consistent with the finding of other study. ${ }^{17}$ In this study only one third of time $(32.2 \%)$ INR was within the target range which is similar to the study of Turpie et al. ${ }^{18}$ There were $21 \%$ of INR readings which was above the target range showing high susceptibility for bleeding complications. In this study more number of patients had INR below the target range $(46.8 \%)$. Study done by Oake et al. ${ }^{19}$ had shown that $48 \%$ of thromboembolic complication occurred at INRs below therapeutic range. However, in this study thromboembolic events reported were very less in relation to INR. This could be because patients were often coursed with aspirin when the INR was close to target range. This could have reduced the risk of thromboembolic events in them. The data of patients using aspirin could not be collected as their prescribing was short term.

In this study, dose adjustment was done most of the time $(82.4 \%)$ when the INR was above the target range. However, when the INR was below the target range there seems to be reluctance in dose adjustment $(61.8 \%)$. As the state of underwarfarinization was often coursed with aspirin when the INR was close to target range; it could be the cause for the observed low frequency of dose adjustment $(61.8 \%)$ when the INR was below the target range. Moreover, low frequency of thromboembolic events in this series also suggests the idea that low INR with aspirin may be an effective anticoagulant.

The present study had several limitations, the first of which is small sample size which might have under or over estimated the result. There were limited numbers of patients with risk factor for complication due to warfarin. Moreover, data on concurrent use of aspirin could not be taken due to its short term prescribing. The study was conducted for three months only, which have created a time limitation. Lastly, it was a single centered study.

\section{CONCLUSIONS}

There is high prevalence of complication related to warfarin in patients with mechanical valve replacement, with bleeding complication being the most prominent one. High incidence of bleeding was probably due to difficulty in tightly controlling INR. Hypertension was found to be significantly associated with major bleeding complication. There was also high fluctuation of INR in patients and mostly INR was below the target range. Moreover, dose adjustment was not done one-third of times, mostly when the INR was below the target range. Hence, patient education, stricter adjustment of INR, frequent monitoring of INR at peripheral hospitals and standardization of the test at different hospitals are suggested to reduce the warfarin related complications. 


\section{ACKNOWLEDGEMENTS}

We would like to thank all staff of surgical unit of SGNHC, whose help and cooperation was a major contribution to this project. We are also thankful to all members of the Department of Pharmacy, Kathmandu University for their encouragement and support throughout the study.

\section{REFERENCES}

1. Goldsmith I, Turpie AGG, Lip GYH. ABC of antithrombotic therapy: Valvar heart disease and prosthetic heart valves. BMJ. 2002;325:1228-31.

2. Cannegieter SC, Rosendaal FR, Briet E. Thromboembolic and bleeding complications in patients with mechanical heart valve prostheses. Circulation. 1994;89:635-41.

3. Gohlke-Bärwolf C. valve disease: Anticoagulation in valvar heart disease: new aspects and management during noncardiac surgery. Heart. 2000;84:567-72.

4. Rahman M, BinEsmael TM, Payne N, Butchart EG. Increased Sensitivity to Warfarin After Heart Valve Replacement. The Annals of Pharmacotherapy. 2006;40(3):397-401.

5. Schulman S, Kearon C. Definition of major bleeding in clinical investigations of antihemostatic medicinal products in nonsurgical patients. J Thromb Haemost. 2005;3:692-4.

6. Acar J, Iung B, Boissel JP, et al. AREVA: multicenter randomized comparison of low-dose versus standard-dose anticoagulation in patients with mechanical prosthetic heart valves. Circulation. 1996;94:2107-12.

7. Aspinall SL, DeSanzo BE, Trilli LE, Good CB. Bleeding Risk Index in an Anticoagulation Clinic. Assessment by Indication and Implications for Care. JGIM. 2005:1008-13.

8. Palareti G, Leali N, Coccheri S, Poggi M, Manotti C, D'Angelo A, et al, on behalf of the Italian Study on Complications of Oral Anticoagulant Therapy. Bleeding complications of oral anticoagulant treatment: an inceptioncohort, prospective collaborative study (ISCOAT). Lancet. 1996;348:423-8.

9. Callejo G, Vila V, Alborch O, Gandía M, Mateu P, Escolano R, et al. A study of the incidence and hospital follow-up of epistaxis in patients treated with anticoagulant acenocoumarol. Acta Otorrinolaringol Esp. 1997;48(5):358-62.
10. Lavy J. Epistaxis in anticoagulated patients: educating an atrisk population. Br J Haematol. 1996;95:195-7.

11. Pisoni CN, Cuadrado MJ, Khamashta MA, Hunt BJ. Treatment of menorrhagia associated with oral anticoagulation: efficacy and safety of the levonorgestrel releasing intrauterine device (Mirena coil). Lupus. 2006;15(12):877-80.

12. Ansell J, Hirsh J, Dalen J, Bussey H, Anderson D, Poller L, et al. Managing Oral Anticoagulant Therapy. Chest. 2001;119:22S385 .

13. Launbjerg J, Egeblad H, Heaf J, Nielsen NH, Fugleholm AM, Ladefoged K. Bleeding complications to oral anticoagulant therapy: multivariate analysis of 1010 treatment years in 551 outpatients. J Internal Med. 1991;229:351-5.

14. Van der Meer FJ, Rosendaal FR, Vandenbroucke JP, Briet E. Bleeding complications in oral anticoagulant therapy. Arch Intern Med. 1993;153(13):1557-62.

15. Petitti D, Strom, B, Melmon, K. Duration of warfarin anticoagulation therapy and the probabilities of recurrent thromboembolism and hemorrhage. Am J Med. 1986;81:2559.

16. Coon WW, Willis PW. Hemorrhagic complications of anticoagulant therapy. Arch Intern Med. 1974;133:386-92.

17. Cannegieter SC, Torn M, Rosendaal FR. Oral anticoagulant treatment in patients with mechanical heart valves: how to reduce the risk of thromboembolic and bleeding complications. J Intern Med. 1999;245:369-74.

18. Turpie AG, Gent M, Laupacis A, et al. A comparison of aspirin with placebo in patients treated with warfarin after heart valve replacement. N Engl J Med. 1993;329:524-9.

19. Oake N, Fergusson DA, Forster AJ, Walraven CV. Frequency of adverse events in patients with poor anticoagulation: a meta-analysis. Can Med Assoc J. 2007;176:1589-94. 